\title{
La planificación estratégica en espacios turísticos de interior: \\ Claves para el diseño y formulación de estrategias competitivas
}

\author{
Daniel Díez Santo \\ Instituto Universitario de Investigaciones Turísticas \\ Universidad de Alicante. \\ daniel.diez@ua.es
}

\section{RESUMEN}

La planificación estratégica en espacios turísticos de interior requiere de un enfoque particular que responda a las necesidades y expectativas del mundo rural. Asimismo, la planificación turística del interior debe contemplar necesariamente la integración de otros espacios como las ciudades intermedias que ayudan a articular y jerarquizar el territorio (capitales comarcales, nodos industriales y comerciales, etc.), y el medio natural donde deben primar los criterios de gestión medioambiental y la sostenibilidad. Por todo ello, la presente investigación pretende identificar empíricamente las líneas estratégicas claves y los aspectos de preferente atención para la planificación efectiva de los espacios turísticos de interior, manteniendo en todo momento como premisas fundamentales el desarrollo local, la competitividad turística y la sostenibilidad territorial.

Para el logro de este doble objetivo se llevó a cabo un intenso y exhaustivo trabajo de campo que tomó como área piloto el interior de la provincia Alicante. Por medio de diferentes técnicas se recabó la opinión de colectivos empresariales e instituciones públicas, que sirvieron de base junto al análisis de numerosas fuentes secundarias, para el diagnóstico de las principales disfunciones de los espacios interiores. Como respuesta a estas disfunciones se presenta una propuesta metodológica que formula y justifica siete grandes ejes estratégicos, que se descomponen a través de diferentes aspectos de atención preferente en la planificación de espacios turísticos de interior.

Palabras clave: turismo de interior, planificación estratégica, desarrollo local, competitividad, sostenibilidad. 


\title{
Strategic planning in inland tourism areas:
}

Keys for the design and formulation of competitive strategies.

\author{
Daniel Díez Santo \\ Tourism Research Institute \\ University of Alicante. \\ daniel.diez@ua.es
}

\section{ABSTRACT}

Strategic planning requires a specific approach that can meet the needs and expectations of the rural world. Inland tourism planning must additionally consider the integration of other spaces, such as medium-sized towns that help articulate and organise the territory into a hierarchy (e.g. small regional or provincial capitals, industrial or commercial hubs, etc.), and the natural milieu, where environmental management and sustainability criteria must always prevail. In the light of the above, the present research work seeks to empirically identify the key strategic lines and aspects of preferential interest for the effective planning of inland tourism areas, keeping at all times local development, tourism competitiveness and territorial sustainability as the essential premises.

In order to achieve this twofold objective, we carried out an intense, comprehensive fieldwork which took the interior of the Alicante Province as its pilot area. Using different techniques, we collected the opinions of business groups and public institutions which, together with the analysis of numerous secondary sources, served as the basis for the diagnosis of the main dysfunctions affecting inland spaces. A methodological proposal is presented in response to these dysfunctions where we formulate and justify seven broad strategic axes which are then broken down into different aspects of preferential attention at inland tourism space planning.

Keywords: inland tourism, strategic planning, local development, competitiveness, sustainability. 


\section{INTRODUCCIÓN}

La planificación turística no responde a un método único y estanco de común diseño e invariable aplicación para cualquier territorio. Según las características inherentes de cada espacio, el proceso, los métodos y sobre todo, los objetivos de la planificación turística pueden variar sustancialmente. La planificación turística es un proceso continuo y flexible, en el marco del cual deben enunciarse recomendaciones de políticas y planes, pero que deben tener la suficiente flexibilidad como para permitir la adaptación a las circunstancias cambiantes de los destinos (Inskeep, 1994). Asimismo, la planificación debe revalorizarse como un proceso continuo e integrado de gestión. La planificación ha de considerarse y tratarse como un componente esencial de la gestión, pero no como un fin en sí mismo. Además, los cambios constantes en el entorno obligan a que la planificación aumente su flexibilidad, al tiempo que se han de mejorar los sistemas de información local y del entorno turístico para construir una verdadera inteligencia competitiva (Ritchie y Ritchie, 2002).

Los planes estratégicos han de servir para responder a las incertidumbres turísticas de los mercados, adecuando las ofertas de productos turísticos de la propia región, comarca - municipio, a las exigencias dinámicas de la demanda. Sin embargo, el aspecto fundamental de la planificación estratégica en turismo es el de la firme convicción de la necesidad de abordar el proceso desde una óptica de involucración del mayor número posible de agentes sociales y económicos. Un plan estratégico es, en esencia, un ejercicio de participación y consenso de todas las fuerzas económicas y sociales con capacidad de decisión e inversión en la mejora del ciclo de vida del producto y la competitividad del territorio turístico (Vera et al., 1997).

Sin embargo, la planificación estratégica en espacios turísticos de interior requiere de un enfoque especial, que responda a las necesidades y particularidades intrínsecas del mundo rural, contemplando asimismo la integración de ciudades intermedias que ayudan a articular y jerarquizan el territorio interior (capitales comarcales, nodos industriales y comerciales, etc.) y los espacios naturales donde han de primar los criterios de gestión medioambiental y sostenibilidad.

Particularmente, el desarrollo turístico en el espacio rural y natural debe ser de carácter extensivo, frente a los desarrollos intensivos del espacio urbano o litoral, de otro modo no podría conservarse la esencia del territorio, que es lo que da la razón de ser al turismo de interior. Ello requiere de un esmerado trabajo de planificación debido a que los recursos que se gestionan son frágiles y vulnerables, porque su conservación es la garantía de permanencia a medio y largo plazo y porque el buen estado de los recursos naturales es el único y más preciado patrimonio con que cuentan muchas poblaciones rurales (Bernabé y Viñals, 1999). En concreto, atendiendo a singularidad específica de los espacios rurales, que se caracteriza por organizarse a partir de microdestinos, pequeñas empresas y productos poco dimensionados (Pulido, 2005), un primer inconveniente que aparece a la hora de planificar estos espacios es su difícil delimitación. La progresiva convergencia entre espacios rurales y urbanos en cuanto a estilos de vida, intercambio funcional, dependencia, etc., dificultan su identificación. En este sentido, pueden distinguirse áreas rurales de influencia urbana, próximas o con elevada accesibilidad respecto a las áreas metropolitanas, con 
problemas asociados de competencias por los usos del suelo. Pero también, transformación paisajística e impacto ambiental, áreas rurales en decadencia afectadas por el ciclo del declive rural y áreas rurales de elevada fragilidad donde a las circunstancias propias del declive rural se suman a un medio físico de difícil accesibilidad (Antón y González, 2005).

Por todo ello, la planificación resulta fundamental para corregir o prever conflictos, siempre que se oriente a través de unos principios básicos: no planificar sin los recursos o atractivos suficientes; diseñar un plan global que permita dar resultados a largo plazo; comenzar con objetivos definidos (aumento de la renta, conservación de la población, etc.); buscar ámbitos de carácter comarcal; contar con la coordinación de estrategias entre la administración pública y la iniciativa privada en la que el capital social cobra un protagonismo creciente; y, sobre todo, no olvidar que los turistas cada vez están más informados, demandan experiencias de calidad, de ahí que la conservación del patrimonio y del entorno natural sean inseparables de la actividad (Orduna, 2002).

\section{METODOLOGÍA}

El objetivo de la presente investigación pasa por identificar las líneas estratégicas fundamentales que debe contener la planificación en espacios turísticos de interior, concretando aquellos aspectos de interés preferente y la manera de abordarlos desde la perspectiva del desarrollo local, la competitividad y la sostenibilidad.

La investigación llevada a cabo, toma como área piloto el interior de la provincia de Alicante, que es analizado exhaustiva y pormenorizadamente tanto desde la dimensión pública como privada. En este sentido, se recogieron opiniones de grupos de acción local, mancomunidades, asociaciones empresariales y ayuntamientos, a través de dinámicas de grupo, entrevistas en profundidad, cuestionarios postales y encuestas telefónicas.

El resultado final de este análisis determina la necesidad de afrontar la planificación estratégica de los espacios turísticos de interior a través de 7 líneas estratégicas fundamentales, que han de abordarse a partir del tratamiento de 21 aspectos clave (Fig. 1). 
Fig. 1. Líneas estratégicas y aspectos fundamentales en el diseño de directrices específicas para espacios turísticos de interior.

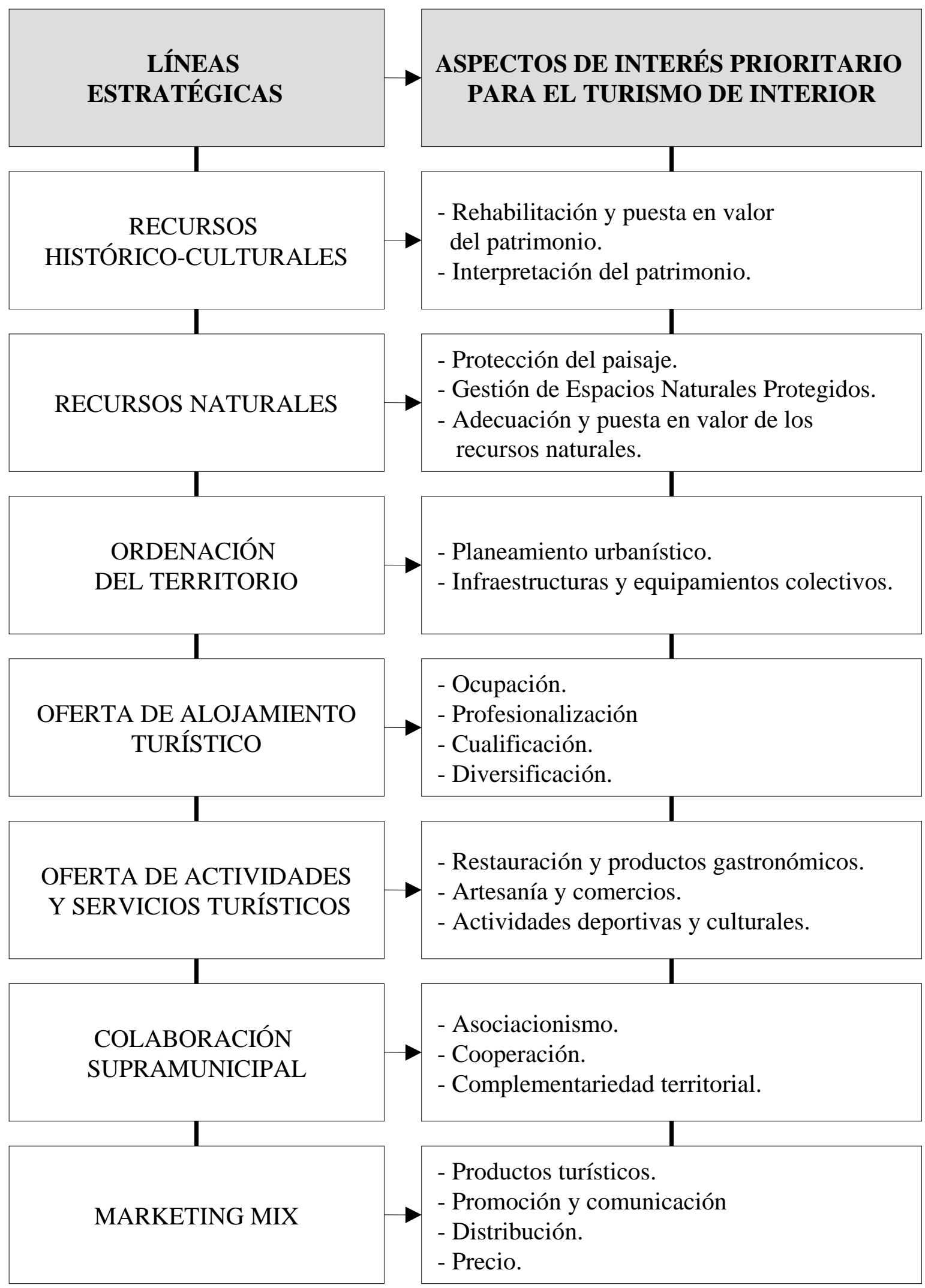

Fuente: Elaboración propia. 


\section{CLAVES PARA EL DISEÑO Y FORMULACIÓN DE ESTRATEGIAS COMPETITIVAS EN ESPACIOS TURÍSTICOS DE INTERIOR}

\subsection{Estrategias sobre recursos histórico-culturales}

Las estrategias sobre recursos histórico-culturales abordan dos aspectos fundamentales para el turismo de interior: la rehabilitación y puesta en valor del patrimonio y la interpretación del patrimonio.

\subsubsection{Rehabilitación y puesta en valor del patrimonio}

La rehabilitación y puesta en valor del patrimonio histórico-artístico juega un papel fundamental para los municipios rurales, que tradicionalmente han visto como su patrimonio monumental iba degradándose progresivamente sin remedio. Afortunadamente, desde los años noventa del siglo XX, el creciente interés por el turismo de interior y la llegada de fondos europeos, ha generado un cambio sustancial en las políticas de puesta en valor del patrimonio histórico. Sin embargo, todavía queda un largo camino por recorrer para recuperar el patrimonio rural y adaptarlo al consumo turístico. En la actualidad, el reparto de las inversiones en materia de rehabilitación del patrimonio aún responde más a intereses políticos que turísticos. Para que esto no siga ocurriendo en el futuro, es necesario introducir nuevos criterios para priorizar las inversiones públicas en esta materia. En este sentido, resulta conveniente considerar la singularidad, el atractivo, el acceso, la accesibilidad, la afluencia de público, la seguridad y el nivel de conservación previo.

\subsubsection{Interpretación del patrimonio}

La interpretación del patrimonio definida por la Asociación para la Interpretación del Patrimonio (AIP) ${ }^{1}$ como "el arte de revelar in situ el significado del patrimonio natural y cultural al público que lo visita en su tiempo libre", es un tema esencial para satisfacer a la demanda turística que visita los espacios interiores.

La interpretación del patrimonio se basa en seis principios fundamentales apuntados por Tilden ${ }^{2}$ : la relevancia del individuo (relacionar el patrimonio con la experiencia y la personalidad de los visitantes a través de mensajes interesantes y cercanos); la transmisión de información y aspectos afectivos (imaginar o revivir los acontecimientos sirviéndose de una información selecta, veraz y de calidad); la interpretación es un arte que puede ser enseñado hasta un cierto punto; se busca la provocación, no la instrucción (actitud positiva hacia el patrimonio por medio de comunicación bidireccional); se presenta el todo y no sólo sus partes; y la interpretación destinada a los niños no debe ser una mera simplificación de la destinada a los adultos.

No obstante, en la actualidad, se deben tener también en cuenta otra serie de consideraciones para la correcta interpretación del patrimonio entre las que destacan

\footnotetext{
www.interpretacióndelpatrimonio.com

${ }^{2}$ Revisados por Beck y Cable (1998), entre otros. Puede consultarse en Morales (1998).
} 
satisfacer las necesidades humanas de seguridad, actualización, estética, autoestima, fisiológicas, etc. y presentar la comunicación de forma atractiva. En este sentido, el mensaje interpretativo ha de ser interesante, atractivo, comprensible, con apariencia de informalidad y con una idea central que envuelva toda la escena y el discurso interpretativo.

Por otro lado, también se ha de tener en cuenta que la interpretación del patrimonio no depende únicamente de la labor del guía, sino que hay que dotar el patrimonio de toda una serie de medios personales y no personales. Entre los medios personales las actuaciones pueden proponer, siempre dependiendo de las características de cada recurso, itinerarios guiados, demostraciones, talleres, animaciones, interpretación ambulante o espontánea, etc. Entre los medios no personales, que son los que requieren mayores niveles de inversión, se pueden proponer señales y marcas para seguir un itinerario (pintadas, incrustadas en el suelo, lectura de códigos y realidad aumentada), publicaciones (folletos, guías y planos), itinerarios autoguiados (audioguías y guías mobile), audiovisuales con medios sensoriales (sonidos, luces y olores), imágenes tridimensionales, paneles interpretativos, etc.

En la actualidad, a parte de los monumentos, existen tres escenarios donde la interpretación del patrimonio juega un papel crucial: los museos, las rutas e itinerarios turísticos y los centros de interpretación o de visitantes.

La nueva museografía desarrollada desde los años ochenta del siglo XX intenta dar respuesta a los cambios sociales producidos desde la revolución cultural de 1968. Entre los principales cambios sociales, culturales y económicos destacan el mayor poder adquisitivo, el mayor nivel cultural (desaparición del analfabetismo, alto porcentaje de universitarios), el mayor tiempo de ocio (reducción de la jornada laboral), la incorporación de la mujer al mundo laboral y universitario, el envejecimiento poblacional y el aumento de los niveles de exigencia de la sociedad. Por su parte, algunas de las principales características de la nueva museología son el traslado del protagonismo del objeto al visitante, la aplicación de técnicas de interpretación, la renovación de contenidos (exposiciones temporales, itinerantes, la pieza del mes, etc.), la renovación expositiva (uso de nuevas tecnologías, explicación de contextos, recreación de ambientes, etc.), la aparición de servicios destinados al usuario (tienda, cafetería, vestíbulo, talleres didácticos, salas de conferencias, etc.), la interactividad de la exposición con el visitante (pantallas táctiles, juegos, réplicas para tocar, etc.) y la descentralización de los museos a partir del desarrollo de museos locales o de sitio.

Las rutas e itinerarios turísticos, cada vez más de moda, representan una magnífica oportunidad para los espacios interiores que pueden beneficiarse de dinámicas de complementariedad territorial. Entre sus principales características destacan la titularidad pública o privada de la ruta, la musealización de los centros históricos, la adaptación a la demanda (duración, ritmo y actividades complementarias), la creación de material promocional para el autoguiado, la instalación de señales y la creación de miradores panorámicos.

Por último, los centros de visitantes, que en teoría son museos de sitio que aplican una importante dosis de técnicas y medios interpretativos, están evidenciando un 
interesante desarrollo sobre todo en parques arqueológicos, culturales o ciudades-museo. Estos centros han de estar en armonía con el entorno, utilizar técnicas de interpretación y combinarse con guías que aporten a las visitas la calidad del trato humano.

\subsection{Estrategias sobre recursos naturales}

Las estrategias sobre recursos naturales tratan tres aspectos fundamentales para el turismo de interior: la protección del paisaje, la gestión de los espacios naturales protegidos y la adecuación y puesta en valor de recursos naturales.

\subsubsection{Protección del paisaje}

La protección de los paisajes rurales y naturales en los espacios interiores es un tema clave para mantener el atractivo turístico de estos espacios. El paisaje puede convertirse en un poderoso factor de atracción, capaz de generar un flujo de visitantes que justifique el desarrollo turístico de un lugar como vemos en multitud de casos (Cànoves et al., 2005). La primera condición de la planificación y gestión de los territorios turísticos es no hipotecar irreversiblemente su calidad paisajística, territorial y ambiental; ciertas decisiones en la política turística relativas a la transformación del entorno paisajístico pueden ser insalvables si no se emprenden con garantías de sostenibilidad y con diseños que puedan ser fácilmente adaptables a los cambios de coyuntura turísticas (Vera et al., 1997).

A la hora de proteger el paisaje es importante integrar la totalidad del territorio y no únicamente las áreas de alto valor paisajístico. Asimismo, se tienen que delimitar los ámbitos territoriales que deban ser objeto de planificación y actuación a escala supramunicipal en materia de paisaje y, en particular, los recorridos escénicos y las zonas de afección visual desde las vías de comunicación. En este sentido, los Estudios de Paisaje deberán contemplar las cuencas visuales de los itinerarios paisajísticos-recreativos, que contribuyan a poner en valor los recursos paisajísticos, facilitando la contemplación del entorno territorial y de las vistas más significativas del lugar, estableciendo zonas de afección de su entorno inmediato e incluso, prohibiendo la edificación y la instalación de elementos artificiales (producción y transporte de energía, torres de telefonía móvil, etc.) en dichas zonas.

Por último, los Programas de Paisaje han de concretar actuaciones para garantizar la preservación, mejora y puesta en valor de los paisajes por su valor natural o cultural. Estos programas comprenden actuaciones de clara incidencia turística como los Programas de Imagen Urbana, los de Restauración dirigidos a la recuperación de áreas deterioradas, o los de puesta en valor de paisajes como recurso turístico. 


\subsubsection{Gestión del turismo en espacios naturales protegidos}

La gestión del turismo en los espacios naturales protegidos ${ }^{3}$ es básica para garantizar que el desarrollo de la actividad turística no suponga una amenaza para el paisaje y la biodiversidad, ni comprometa la conservación de los hábitats de flora y fauna silvestres. En este sentido, toda actividad turística que se lleve a cabo en espacios naturales protegidos debería respetar la regulación del uso turístico, así como las normas y directrices de uso público contenidas en sus respectivos Planes Rectores de Uso y Gestión (PRUG ${ }^{4}$ ) y, también, en los correspondientes Planes de Ordenación de los Recursos Naturales (PORN ${ }^{5}$ ). Asimismo, cobran importancia y protagonismo la aplicación de los Sistemas de Calidad Turística en los Espacios Naturales Protegidos y la complementariedad de este modelo con la Carta Europea de Turismo Sostenible.

A modo de ejemplo, la Guía para la Planificación del Uso Público de la Comunitat Valenciana (Conselleria de Medio Ambiente, Agua, Urbanismo y Vivienda), establece una serie de recomendaciones para la planificación de actividades, servicios y equipamientos en Espacios Naturales Protegidos (ENP), que han sido recogidas a su vez en el Plan de Espacios Turísticos de la Comunitat Valenciana (Conselleria de Turisme, 2007). Según estas recomendaciones, las actividades propuestas para ENP deben basarse en los valores del espacio natural, asegurando la conservación del patrimonio natural y cultural del espacio protegido, adecuando la intensidad de uso a la capacidad de acogida del lugar (evitar zonas ambientalmente frágiles o sensibles), primando la intención educativa como mecanismo para fomentar la concienciación ambiental y el acercamiento del visitante al patrimonio natural, cultural y etiológico. Asimismo, el desarrollo de actividades ligadas al uso público debe tratar de priorizar lugares de uso público consolidado, lugares con elementos naturales o culturales de especial interés, el entorno inmediato de los núcleos de población, las principales vías de acceso y los lugares con buenas condiciones para la instalación de nuevos equipamientos si se estima necesario. Todo ello, sin olvidar el seguimiento y la evaluación de las actividades de uso público, con atención especial a los efectos sobre el medio natural y a la calidad de la visita, debiendo aplicarse medidas de corrección cuando sea necesario.

La apropiada dotación de infraestructuras y equipamientos juega un papel determinante en la gestión del uso público de espacios naturales. Por este motivo, el espacio natural protegido debe tener una oferta de instalaciones, servicios y actividades de uso público adecuada a las características del mismo, ajustada a la demanda, que responda a los objetivos de gestión y que cumpla con las recomendaciones de calidad para su aprovechamiento turístico. Lo más recomendable es que la distribución de los equipamientos sea regular y evite su concentración y la masificación de visitas en determinados sectores o zonas, procurando además una buena accesibilidad general

\footnotetext{
${ }^{3}$ Los Espacios Naturales Protegidos reúnen diferentes valores científicos, ecológicos, paisajísticos, culturales, sociales, didácticos y recreativos, en relación a los cuales cumplen diferentes funciones (conservación de la naturaleza, espacio residencial y productivo, usos recreativos y turísticos, etc.).

${ }^{4}$ Los PRUG establecen la regulación de usos y actividades y los programas de actuación, entre los que se incluyen los de educación ambiental y uso público, este último acompañado en muchas ocasiones del uso turístico.

${ }^{5}$ Los PORN responden a la necesidad de integrar la planificación de los recursos naturales en el marco territorial más allá de los límites de los Espacios Naturales Protegidos, con consideraciones relativas a las zonas periféricas de protección y de influencia socioeconómica.
} 
(acceso transitable, cómodo, próximo, etc.), que incluya la adecuación para personas con minusvalías allá donde las condiciones del lugar lo permitan. Asimismo, deberá potenciarse el acceso al espacio natural protegido mediante sistemas no motorizados, promoviendo la práctica de recorridos pedestres y otras formas de conocimiento del espacio natural de forma ordenada y bajo premisas de sostenibilidad.

Los equipamientos de nueva creación han de adecuarse a las aptitudes ambientales de las zonas donde se establezcan, así como a la demanda existente o potencial de visitantes, teniendo garantizada la correcta ejecución de los servicios. De este modo, la rehabilitación del patrimonio edificado ha de primar sobre la construcción de nuevos edificios para albergar equipamientos, promoviendo en todo caso la rehabilitación de construcciones que resulten de interés por sus características arquitectónicas, etnográficas, paisajísticas o ambientales. Por otro lado, resulta también crucial que el diseño y funcionamiento de los equipamientos responda a un conjunto de "buenas practicas ambientales", que debe incluir el aprovechamiento energético, la racionalización del uso del agua, la gestión de residuos, la reducción del uso de productos nocivos y la integración en el medio, promoviendo la arquitectura bioclimática, para considerar los factores ambientales desde el propio diseño del edificio.

En cuanto al uso del espacio protegido ha de procurarse una correcta adecuación de la red de sendas, mejorando las condiciones de seguridad de su recorrido, manteniendo y renovando la señalización de los mismos, de manera que se adapte a las necesidades educativas y a la difusión de los valores naturales, culturales y paisajísticos del espacio natural. Ello contribuye indirectamente a la protección del espacio natural que deberá completarse con la adopción de medidas de vigilancia a través del voluntariado ambiental en las épocas y lugares más frecuentados para evitar los riesgos sobre los recursos naturales y las personas.

Las técnicas de interpretación son fundamentales en todos los programas de uso público para descubrir al visitante los principales valores del patrimonio natural y cultural con la ayuda de medios ilustrativos, con experiencias de primera mano y de manera personalizada o no. Asimismo, los programas de comunicación, orientados a visitantes y habitantes del espacio protegido, han de dirigirse preferentemente al conocimiento de sus valores naturales y culturales, a la sensibilización sobre la necesidad de conservar estos valores, a la información sobre equipamientos, actividades y servicios de uso público y a la difusión de la normativa vigente, de forma que aclare las conductas recomendables y las condiciones para la realización de actividades en el espacio natural protegido.

En cuanto a la gestión del ENP, resulta más que recomendable la búsqueda de fórmulas de gestión del uso público (equipamientos y servicios), que permitan su explotación por las organizaciones empresariales locales. No obstante, las iniciativas que puedan realizarse por otras entidades deberán estar coordinadas con la programación que realice la administración pública que gestione el área protegida. En cualquier caso, siempre se potenciará la aplicación de criterios de calidad en los servicios y los equipamientos de uso público, en cuanto al diseño, la gestión, los equipos humanos responsables y el proyecto educativo. 


\subsubsection{Puesta en valor de los recursos naturales}

La puesta en valor de los recursos naturales juega un papel crucial para el turismo de interior, sobre todo si te tiene en cuenta que los recursos naturales son el principal atractivo que motiva la visita de la demanda turística. Por ello, se ha de tener la máxima sensibilidad y cuidado a la hora de integrar el uso turístico y la conservación de los recursos, ya que si el desarrollo turístico no es sostenible se acaba por destruir el reclamo que atrae a la demanda. En este punto es donde cobran especial protagonismo los estudios de capacidad de carga. En líneas generales, la capacidad de carga turística se puede definir como "la identificación del número máximo de personas que visitan un espacio sin provocar ni una inaceptable alteración del medio físico, ni una inaceptable reducción de la calidad de la experiencia de los visitante» (Ivars, 2001).

La capacidad de carga de un destino puede atender a cuatro tipologías: capacidad de carga física (umbral a partir del que cual se daña el medio ambiente y los recursos culturales), capacidad de carga económica (umbral a partir del cual el turismo dificulta el funcionamiento de otras actividades económicas), capacidad de carga social (umbral a partir del cual se dificultan funciones sociales y se empiezan a generar tensiones con la población residente) (Vera et al., 1997) y capacidad de carga institucional (capacidad de las administraciones públicas para regular y controlar el crecimiento turístico (Butler cit. en Ivars et al. , 2001). Partiendo de las premisas anteriores, entre las actividades turísticas a proponer en espacios interiores se primarán las basadas en el conocimiento, interpretación y disfrute de los valores naturales y culturales del espacio natural protegido y sus zonas aledañas, en especial aquellas no asociadas a la construcción de edificaciones ni infraestructuras, y dirigidas a completar la oferta de uso público y recreativo. En general, se trata de favorecer las iniciativas dirigidas a la producción de experiencias que induzcan al comportamiento responsable de los turistas, prefiriendo las de carácter contemplativo y mayor contenido educativo frente a las deportivas o de aventura. En este sentido, algunas de las actividades a potenciar pueden ser la observación de aves, la interpretación de la naturaleza, la fotografía de naturaleza, los recorridos paisajísticos, las visitas guiadas, la educación ambiental, la acampada libre, el senderismo, los paseos a caballo, la recogida responsable de setas, la visita de refugios y centros de recuperación de la fauna, las rutas ornitológicas, botánicas, geológicas, así como todas aquellas que contribuyan a poner en valor el patrimonio natural y el paisaje.

\subsection{Estrategias sobre ordenación del territorio}

La ordenación del territorio va más allá de la mera delimitación de zonas, representando en la actualidad una opción indispensable de consenso socioeconómico y un instrumento clave para la armonización territorial. Factores y elementos como la competencia por el espacio entre diferentes usos y actores sociales, la complejidad de los procesos de globalización y su traducción en una competencia entre ciudades y regiones a partir del uso como recurso de su territorio, la existencia de espacios especialmente vulnerables a la acción antrópica, la necesidad de establecer mecanismos de cooperación, cohesión y equilibrio interregional, la coexistencia de intereses de protección y explotación 
del territorio, convierten en imprescindible la ordenación del territorio para garantizar un funcionamiento integrado y racional del espacio (Antón y González, 2005). Asimismo, la ordenación del territorio debe apoyarse en cuatro principios básicos: eficiencia, equidad, jerarquía y complementariedad (Gómez, 1994).

En una aproximación a la cuestión, las estrategias sobre ordenación del territorio han de tratar, al menos, dos cuestiones básicas para la planificación turística de los espacios de interior: el planeamiento urbanístico y las infraestructuras y equipamientos colectivos con incidencia sobre el turismo.

\subsubsection{Planeamiento urbanístico}

La tipología y características del planeamiento urbanístico inciden directamente sobre las posibilidades y la calidad del turismo tanto en los destinos, como en los espacios turísticos interiores de carácter supramunicipal. Por ello, el territorio susceptible de aprovechamiento turístico ha de reunir unos requisitos funcionales en cuanto a servicios e infraestructuras, además de elementos de atracción y una imagen turística diferenciada. En este punto es donde cobran mayor protagonismo los instrumentos de ordenación del territorio para alcanzar un desarrollo turístico sostenible en los espacios interiores (nuevos Planes de Acción Territorial, umbrales y cuotas de sostenibilidad ${ }^{6}$, etc.), además de otras directrices tendentes hacia la recuperación de centros históricos y su dinamización turística, la mejora de la movilidad urbana, la cualificación de los núcleos rurales y el control de la urbanización extensiva.

Para mantener el dinamismo económico, mejorar la calidad de vida residencial y asegurar la competitividad turística de los destinos turísticos es necesaria la introducción de mecanismos de renovación de los centros urbanos encaminados hacia la ampliación y mejora del espacio público (zonas verdes, áreas peatonales, parques infantiles, etc.), creación de plazas de aparcamiento sobre todo en áreas comerciales, mejora de la imagen urbana, recuperación del patrimonio histórico-artístico, dinamización de la actividad comercial y cultural, compatibilización de usos comerciales, lúdicos y residenciales, creación de rutas turísticas a partir de nodos de transporte público y mejora de la señalización y el mobiliario urbano.

Otro tema que ha cobrado especial protagonismo durante los últimos años, sobre todo antes de la irrupción de la actual crisis económica, es el traslado del modelo de crecimiento urbanístico litoral hacia los espacios interiores. El modelo de urbanización extensiva genera importantes disfunciones como el consumo de suelo, el incremento del coste en la provisión de servicios y dotación de infraestructuras, e incluso favorece pautas de ocupación estacional. Para evitar estas disfunciones, las directrices en materia de planificación han de proponer actuaciones encaminadas hacia el fomento de modelos urbanos compactos que mejoren la eficiencia territorial, pero también introducir criterios de capacidad de acogida, asegurar la consolidación de zonas urbanizables antes de proveer

\footnotetext{
${ }^{6}$ Se fija un límite a la ocupación del suelo a partir del cual los municipios deben afrontar compensaciones económicas (cuotas de sostenibilidad) destinadas al Fondo de Equidad Territorial.
} 
otras nuevas y fomentar la elaboración de Planes de Reforma Interior ${ }^{7}$, sobre todo en los centros históricos.

\subsubsection{Infraestructuras y equipamientos colectivos}

Las dotaciones en materia de infraestructuras y equipamientos colectivos desempeñan un papel básico para el correcto desarrollo y la competitividad turística del territorio. En este sentido, la calidad de los sistemas viarios resulta fundamental para el turismo, tanto dentro de las propias comarcas interiores, como también en los ejes de comunicación que ponen en contacto el litoral con el interior. De forma paralela, también son importantes las conexiones ferroviarias entre los principales núcleos urbanos y la progresiva recuperación de las antiguas líneas férreas para usos turísticos (vías verdes).

Por otro lado, los aeropuertos desempeñan un papel clave para la captación de demanda turística extranjera, una de las principales necesidades del turismo de interior. Por este motivo, se hace imprescindible habilitar medios de transporte colectivo que favorezcan la intermodalidad hacia las principales capitales comarcales de los espacios interiores.

La correcta gestión del agua es una obligación, sobre todo en aquellos territorios que reciben menores precipitaciones y soportan fuertes periodos de indigencia hídrica. Por este motivo, se deben optimizar al máximo los sistemas de saneamiento, depuración y reutilización de aguas, limitar y controlar las captaciones de aguas freáticas, reducir al máximo las pérdidas hídricas en las canalizaciones, limitar las actividades y usos turísticos que supongan consumos excesivos de agua (golf, turismo residencial, etc.), introducir Sistemas de Gestión Medioambiental que mejoren la eficiencia hídrica y energética de las empresas turísticas (Normas ISO 14.001) y poner en valor las láminas de agua susceptibles de aprovechamiento turístico (pantanos, cursos fluviales, etc.).

Asimismo, se debe apostar decididamente por la correcta gestión de residuos (recogida selectiva, transporte y tratamiento), controlando al máximo la aparición de escombreras y vertederos incontrolados que suponen importantes riesgos medioambientales (contaminación freática por falta de impermeabilización del suelo, riesgo de incendios forestales, alteraciones en los comportamientos de los animales, etc.) y fuertes impactos visuales para la demanda turística.

En materia de equipamientos colectivos es prioritario disponer de centros sanitarios públicos de calidad, que garanticen el acceso universal a la sanidad pública de los habitantes de los municipios interiores y de los turistas que los visitan. Para ello, es necesario dimensionar correctamente las infraestructuras sanitarias respecto a la población actual, introduciendo parámetros de dispersión geográfica (áreas rurales) y de crecimiento estacional de la población (turistas y residentes vacacionales).

Los equipamientos deportivos también juegan un papel destacado que puede incidir directamente en los niveles de satisfacción y fidelidad de la demanda que visita los espacios

\footnotetext{
${ }^{7}$ Planes de rehabilitación de viviendas basados en estrategias de aprovechamiento turístico (oferta de alojamiento, comercios, turismo residencial, etc.). respetando tipologías, morfologías, imagen y carácter del casco urbano tradicional.
} 
interiores. La capacidad para el disfrute de actividades deportivas en el medio natural, pero también en instalaciones adaptadas para tales fines, constituye un atractivo adicional para el turista. Sin embargo, no todas las instalaciones deportivas son aconsejables para el medio rural, debiendo fomentarse aquellas instalaciones que supongan un menor impacto ambiental (polideportivos, centros deportivos de alto rendimiento, centros de aventura debidamente acotados ${ }^{8}$, actividades acuáticas de bajo impacto, etc.). En este sentido, se tendrá que tener la máxima prudencia a la hora de estudiar la instalación de campos de golf, sobre todo si llevan consigo nuevos desarrollos urbanísticos.

Por último, el mantenimiento de la oferta comercial tradicional en el mundo rural supone un interesante reclamo para el turista (productos autóctonos y artesanías), al tiempo que contribuye al desarrollo local. Por este motivo resulta aconsejable potenciar fórmulas comerciales propias ligadas a la identidad de los municipios y a la comercialización de productos tradicionales.

\subsection{Estrategias sobre oferta de alojamiento turístico}

Las estrategias sobre oferta de alojamiento turístico en ámbitos interiores han de centrarse, al menos, en cuatro aspectos prioritarios para la correcta operatividad de la actividad turística: ocupación, profesionalización, cualificación y diversificación.

\subsubsection{Ocupación de los alojamientos}

Uno de los principales problemas que presenta el turismo rural es la baja ocupación de los alojamientos, que incide directamente sobre la rentabilidad y la capacidad de inversión de las empresas. Este problema es difícil de solucionar, ya que deriva de múltiples factores y arrastra infinidad de consecuencias.

En los últimos años, la ocupación de los establecimientos rurales se ha visto mermada por el descenso de las pernoctaciones, la reducción de la estancia media, la estacionalidad y la "sobreoferta", provocando incluso el cierre de los alojamientos con menor capacidad competitiva. A grandes rasgos, las actuaciones para aumentar la ocupación de los alojamientos de interior deberán girar en torno a la captación de mercados extranjeros para la desestacionalización y ampliación de la estancia media, la homogenización de la oferta para la captación de grupos a través de agencias de viajes y turoperadores específicos, la ampliación del tamaño de los establecimientos, la captación de segmentos de demanda alternativos durante los días de entre semana (negocios, estudiantes, etc.), la paquetización junto a ofertas complementarias y la creación de ofertas y descuentos fuera de temporada.

\subsubsection{Profesionalización de la oferta}

En un mundo globalizado en el que la oferta es cada día más competitiva, la profesionalidad debe medirse por la capacidad para responder a las expectativas de una

\footnotetext{
${ }^{8}$ Terrenos sobre los que se acotan actividades de aventura como tirolinas, rocódromos, paint ball, tiro con arco, yincanas, túneles, pasarelas móviles, etc.
} 
demanda más exigente en la relación calidad/precio. Este problema se acentúa en el medio rural, cuando, ante una elevada demanda estacional, se acude a contratar personal de vecindad, buscando más una reducción de costes laborales y una lealtad con respecto al patrimonio familiar, que una mayor cualificación $y$, consecuentemente, también, mayor calidad de servicio (Pardellas, 2008).

A pesar de que en los últimos años se ha avanzado notablemente en la profesionalización de la oferta, sobre todo gracias a las acciones formativas emprendidas por los grupos de acción local, centros de desarrollo turístico y universidades, todavía resulta necesario un cambio de mentalidad en el empresariado si se quiere disponer de una oferta turística verdaderamente competitiva. Aunque inicialmente el turismo rural vinculado al desarrollo local se entendía como una fórmula para complementar rentas, en la actualidad la oferta que no se gestione de un modo profesional está condenada al fracaso. Por ello, resulta básico proponer actuaciones que fomenten la formación continua de empresarios y empleados (gestión empresarial, nuevas tecnologías, promoción y comercialización, idiomas, etc.), estimulen la aparición de empresarios emprendedores con dedicación plena al negocio y minimicen la precariedad laboral del sector turístico.

\subsubsection{Cualificación de la oferta}

La cualificación de la oferta gana mayor protagonismo en el contexto actual donde la demanda cada vez es más exigente (mayor acceso a la información, facilidad de comparación, mayor experiencia a la hora de viajar, búsqueda de comodidades y servicios, etc.). Por todo ello, las empresas turísticas han de apostar por el concepto de Calidad Total, a través de la implantación de Sistemas de Gestión de la Calidad (ISO 9001, Q del ICTE, Normas UNE, Clubs de Prestigio o de Producto, Normativas específicas de las administraciones autonómicas, etc.), que mejoren la calidad de las instalaciones y los servicios prestados y el nivel de formación y profesionalización de los empleados. Sin embargo, la calidad que esperan los clientes de los alojamientos rurales depende también de otra serie de intangibles tales como el trato familiar o la autenticidad, que deben ser tenidos muy en cuenta si se pretende responder a las expectativas de los visitantes que acuden al medio rural.

\subsubsection{Diversificación de la oferta}

La diversificación de la oferta es el último elemento fundamental a considerar en el diseño de directrices sobre oferta turística. La actual diversidad de segmentos de demanda obliga a responder con una diversidad proporcional de ofertas, que evite el mimetismo y apueste por la singularidad y la innovación productiva. Para evitar situaciones de sobreoferta en los ámbitos interiores, especialmente de casas rurales, resulta cada vez más necesario introducir nuevas fórmulas de oferta de alojamiento para captar otros segmentos de demanda diferentes (agroturismo y turismo enológico, campings y zonas de acampada, refugios y cabañas en plena montaña, hoteles con encanto, balnearios, albergues vinculados a actividades deportivas y de educación ambiental, casas rurales tematizadas, alojamientos en edificios de interés histórico-cultural, etc.). 


\subsection{Estrategias sobre oferta de actividades y servicios turísticos}

Cada vez resulta más habitual que las actividades y servicios turísticos abandonen su carácter complementario para convertirse en el principal motivo de la visita a los destinos turísticos. Por esta razón, se hace necesario el diseño de estrategias específicas sobre oferta no alojativa, que traten con detalle aspectos como la restauración y los productos gastronómicos, el comercio, la artesanía y las actividades deportivas y culturales.

\subsubsection{Restauración y productos gastronómicos}

Sin lugar a dudas, una de las principales motivaciones por las que los turistas y sobre todo los visitantes diarios acuden a los municipios interiores es el deleite de la gastronomía típica. Por este motivo, se deben proponer actuaciones que fomenten la conservación de las tradiciones gastronómicas (platos genuinos de cada lugar, productos autóctonos, inclusión de las recetas tradicionales en las cartas y menús de los restaurantes, etc.) y que estimulen e incentiven la creación de nuevos restaurantes de calidad en los que conviva la cocina tradicional con la cocina de autor más vanguardista.

\subsubsection{Artesanía y comercio}

La artesanía y el comercio son dos actividades claves para el desarrollo rural que pueden alinearse con la actividad turística para obtener beneficios mutuos. Los espacios interiores capaces de mantener vivas sus tradiciones artesanales tienen en la autenticidad una magnífica ventaja comparativa difícilmente reemplazable. Sin embargo, para que el turista pueda adquirir artesanías es necesario aportar algunas facilidades tales como la organización de visitas a los talleres artesanos (para valorar el producto se tiene que ver el proceso de elaboración), la adaptación de los productos a las necesidades e intereses de la demanda (precio, tamaño, utilidad, variedad y estética), la exposición de productos en alojamientos, restaurantes y oficinas de información, así como el establecimiento de horarios de apertura concretos (horarios estables y garantía de apertura durante los fines de semana y festivos).

Otro factor fundamental para fomentar la artesanía y los productos locales son los propios comercios. El equipamiento comercial, además de satisfacer las necesidades de la población local, tiene una incidencia en la calidad de la estancia del visitante, ya que éste requiere de productos y servicios (Andreu et al., 2005). La profesionalización de la actividad comercial es básica para aumentar el gasto turístico en los destinos rurales. El turista siempre está dispuesto a adquirir productos, pero los comercios deben de saber venderlos correctamente (escaparatismo atractivo, horarios fijos, tiendas multiproducto, nociones básicas de inglés, correcta organización y etiquetado de los productos, etc.).

\subsubsection{Oferta de actividades deportivas y culturales}

La oferta de actividades deportivas y culturales en los destinos turísticos de interior es fundamental para mejorar la experiencia vacacional del turista y en definitiva, ayudar a ocupar su tiempo libre de un modo satisfactorio. Sin una diversificada oferta de actividades 
"complementarias", la demanda turística que acude a los municipios rurales difícilmente aumentará la estancia media y la fidelidad al destino. Por todo ello, se tienen que proveer actuaciones encaminadas hacia la implantación de actividades innovadoras que estimulen, entretengan, diviertan, pero también, formen y conciencien al turista. En este sentido, el abanico de posibilidades es tan amplio como la imaginación del empresario emprendedor (actividades multiaventura, geocaching ${ }^{9}$, yincanas, paint ball, excursiones en globo aerostático, espeleología, orientación, noches de terror, resolver un crimen ficticio, educación ambiental, recogida de setas, prácticas idiomáticas, safaris fotográficos, recogida de productos hortofrutícolas, observación astrológica, juegos de rol, encuentros de solteros, ambientación, recreación, disfraces, etc.). En este punto, lo esencial es formar a los emprendedores y tratar de avalar aquellos proyectos más viables por parte de las administraciones competentes (promoción, comercialización, subvención).

\subsection{Estrategias sobre colaboración supramunicipal}

El desarrollo de mecanismos de colaboración a escala municipal y sobre todo supramunicipal, es básico para elevar la competitividad de los destinos y los espacios turísticos de interior. En este sentido, las directrices propuestas deben centrarse en tres aspectos de capital importancia: el asociacionismo, la cooperación y la complementariedad territorial.

\subsubsection{Asociacionismo}

Aunque a nadie se le escapa que en el medio rural el asociacionismo y las iniciativas mancomunadas son fundamentales para el desarrollo de cualquier actividad económica, en el caso concreto del turismo, la competencia entre las microempresas impide consensos mayoritarios y la creación de asociaciones de elevada representación. La tónica dominante suele ser la continua desagregación y aparición de nuevas asociaciones formadas por un número reducido de miembros. Ante este panorama, las actuaciones a proponer han de encaminarse hacia la creación de entes de gestión mixta formados por empresarios y la administración local, asociaciones de carácter comarcal, clubes de producto y federaciones en las que se incluyan todas las asociaciones de un espacio turístico concreto (provincia, comunidad autónoma, marca turística, etc.).

\subsubsection{Cooperación}

La falta de cooperación, especialmente entre instituciones, puede acarrear toda una serie de problemáticas poco deseables: falta de racionalidad en inversiones, falta de equidad, duplicidad de tareas, descoordinación, solapamiento de funciones, dispersión de fondos y desinformación (Solsona, 2009). Por todo ello, resulta imperativa la constitución de comisiones interadministrativas e interdepartamentales de integración vertical (local, comarcal, provincial, autonómica, nacional) y transversalidad horizontal (patrimonio, medio ambiente, infraestructuras, sanidad, urbanismo, comercio, cultura), que mejoren la eficiencia y la continuidad de las políticas turísticas planteadas.

\footnotetext{
${ }^{9}$ Búsqueda de tesoros escondidos con la ayuda del GPS.
} 


\subsubsection{Complementariedad territorial}

La complementariedad territorial es y será sobre todo en el futuro, un elemento esencial para los destinos turísticos, tanto interiores como litorales. Los municipios interiores evidencian una endémica falta de ocupación arrastrada por la estacionalidad y la corta duración de la estancia media. Los destinos rurales son visitados básicamente durante puentes y fines de semana, porque individualmente, no reúnen los suficientes atractivos para prolongar la estancia de una demanda cada vez más exigente. Por este motivo, la colaboración supramunicipal entre los propios municipios interiores, resulta clave para aumentar las posibilidades y atractivos de estos espacios (organización de eventos itinerantes de suficiente entidad turística, articulación de rutas e itinerarios turísticos reales, creación de productos innovadores a partir de la yuxtaposición de recursos afines, asociacionismo empresarial para la creación de redes de alojamientos homogéneos, creación de paquetes y circuitos turísticos bien estructurados, mecanismos de promoción y comercialización conjunta, diseño de planes estratégicos de carácter mancomunado, etc.).

Por su parte, los destinos maduros del litoral están empezando a encontrar límites a su crecimiento en la capacidad de carga de sus playas, al tiempo que necesitan nuevos elementos originales para diversificar y romper el mimetismo de la oferta complementaria. En la actualidad, todas estas cuestiones cobran un interés capital para satisfacer a la demanda y mantener su fidelidad al destino. Llegado este punto, es donde las dinámicas de complementariedad territorial litoral-interior, a través de movimientos pendulares de flujos turísticos, pueden generar una simbiosis turística que beneficie a ambos espacios. Pero también, pueden traer consigo numerosas sinergias que estimulen y dinamicen el transporte, el comercio y la artesanía. En este sentido, los destinos litorales que apuesten por la integración de espacios interiores, podrán aumentar su posicionamiento y capacidad competitiva al sumar nuevos valores diferenciadores durante el proceso (singularidad, diversidad, innovación, calidad, autenticidad, sostenibilidad y solidaridad).

\subsection{Estrategias sobre marketing mix}

El marketing mix también conocido como mezcla de mercadotecnia, mezcla comercial o mix comercial son las variables de que se disponen en mercadotecnia para cumplir los objetivos estratégicos. El concepto fue desarrollado Borden (1964) a través de una lista de 12 factores $^{10}$, que simplifica McCarthy (1960) constituyendo las archiconocidas "Cuatro P's" del marketing (Producto, Promoción, Plaza o Distribución y Precio). En 1984 la AMA (Asociación Americana de Marketing) consagró el término al definir el marketing como el "proceso de planificación y ejecución del concepto de precio, promoción y distribución de ideas, bienes y servicios para crear intercambios que satisfagan los objetivos del individuo y la organización". Más recientemente, con el desarrollo de la industria de los servicios y sectores sociales se han ido agregando nuevas $\mathrm{P}^{\prime} \mathrm{s}$ al concepto marketing mix: Personal, Procesos, Presentación, Parking (estacionamiento) en retail marketing, Partner (socio) dada la importancia de las asociaciones y Profesor en marketing educacional.

\footnotetext{
${ }^{10}$ Los 12 factores originales propuestos por Neil Borden fueron "Product policy, Servicing, Packaging, Display, Promotions, Branding, Personal Selling, Advertising, Pricing, Channels of Distribution, Physical Handing and Fact finding and Analysis".
} 


\subsubsection{Producto}

El producto se puede definir como todo aquello tangible o intangible, que se ofrece a un mercado para su adquisición, uso o consumo y que puede satisfacer una necesidad o un deseo. Por lo tanto, pueden considerarse productos tanto objetos materiales y bienes como servicios, personas, lugares, organizaciones o hasta incluso ideas.

En materia turística el producto es principalmente un conjunto de servicios compuesto por una combinación de elementos que presentan toda una serie de características diferenciadoras y propias de la actividad turística: intangibilidad (los servicios no pueden ser propiedad de un consumidor, sino que son ejecutados y evaluados en base a unos resultados y experiencias); caducidad (los servicios son perecederos, si no se usan en un momento concreto se pierden para siempre al no poderse almacenar); inelasticidad de la oferta (los productos turísticos no se adaptan bien a los cambios a corto plazo de la demanda, ya que dependen de toda una serie de infraestructuras ya existentes como hoteles, transportes, habitaciones disponibles, etc.); elasticidad de la demanda (la demanda de productos turísticos reacciona rápidamente ante cambios del entorno o amenazas en la seguridad, cambios económicos o la aparición de nuevas tendencias de moda); complementariedad (el producto turístico no es un servicio único, sino que se compone de varios sub-productos complementarios y si se produce un fallo en alguno de ellos la calidad total del producto final puede verse comprometida); inseparabilidad (el proceso de producción y consumo tiene lugar al mismo tiempo sin haber transferencia de propiedad); heterogeneidad (el producto turístico debido a los servicios prestados es imposible de repetir idénticamente); elevados costes fijos (el coste inicial en proporcionar los elementos básicos del turismo como transporte y alojamiento es muy alto y se necesitan fuertes inversiones sin garantía de que la inversión sea utilizada plenamente y los beneficios futuros no están asegurados); e intensivo en mano de obra (la calidad del servicio ofrecido depende en gran medida de las habilidades del personal contratado por las empresas turísticas).

En mercadotecnia existen cuatro generaciones de estrategias fundamentales para los productos turísticos: estrategias de penetración para incrementar la cuota global del mercado ofertando el mismo producto existente sin incorporar ninguna modificación o mejora; estrategias de desarrollo del producto turístico para actuar sobre los mercados turísticos actuales incorporando nuevos productos que surjan como variaciones de los productos turísticos existentes (extensiones de la línea básica o con productos sustitutivos); estrategias de extensión del mercado turístico que utilizan el mismo producto turístico intentando atraer nuevos consumidores (nuevos segmentos de mercado); y estrategias de diversificación turística encaminadas hacia el desarrollo de nuevos productos basados en la satisfacción de nuevos clientes, con nuevos destinos turísticos y con la incorporación de nuevas actividades turísticas. A su vez éstas estrategias pueden ser horizontales (mayor cobertura del mercado turístico con una amplia gama de productos turísticos para clientes con comportamientos similares a los ya existentes), verticales (captación de nuevos mercados a través de actividades poco diferentes de las actuales) y concéntricas (presentación más integrada de los servicios que componen el producto turístico, dotando de mayor homogeneidad a la organización turística en los mercados a través de imagen, calidad, etc.). 
En los espacios turísticos de interior el problema viene cuando los propietarios de alojamientos rurales confunden la existencia de paisajes, ríos, montañas e, incluso, monumentos o fiestas tradicionales, con la disponibilidad efectiva de productos $y$, así, lo trasladan a sus folletos o páginas de Internet. En demasiadas ocasiones se ignora que tales recursos sólo constituyen la materia prima para su empresa y que el producto en un destino concreto es la agregación a esa materia prima de su oferta de alojamiento, más las ofertas de actividades de turismo activo, más la oferta gastronómica, más los servicios y equipamientos generales del entorno, más la cualificación del personal que atiende a los turistas, etc. La falta de interrelación entre esos componentes genera un producto desestructurado y confuso, que, con frecuencia, causa insatisfacción al cliente, acentuada por el hábito, desafortunadamente extendido hoy en el mundo rural, de cobrar precios no homologables con el resto del mercado turístico (lo que podría definirse en términos coloquiales como exprimir al turista hoy porque quizá no venga otro mañana) (Pardellas, 2008).

Para estos espacios interiores lo más recomendable sería afianzar los productos turísticos actuales (turismo rural, turismo de naturaleza, turismo deportivo o de aventura, etc.) e ir introduciendo nuevos productos innovadores y potencialmente compatibles con los ya existentes (espacio ocupado, intereses de los segmentos de demanda, gasto turístico, etc.). Al mismo tiempo, los nuevos productos turísticos a implementar en los espacios interiores deberán cumplir tres preceptos básicos: la aceptación por parte de la población local, el bajo impacto ambiental y la contribución al desarrollo local. El incumplimiento de alguno de los tres preceptos anteriores debería ser motivo de exclusión. No obstante, existen infinidad de productos turísticos que se pueden implantar y desarrollar perfectamente en los espacios interiores, tanto rurales, naturales, como urbanos (turismo industrial, agroturismo, enoturismo, turismo de salud y belleza, turismo cultural, turismo idiomático, turismo de negocios y congresos, turismo gastronómico, etc).

\subsubsection{Promoción}

La promoción puede definirse como la transmisión de información del vendedor al comprador, cuyo contenido se refiere al producto o a la empresa que lo elabora o lo vende. La promoción puede ser realizada a través de distintos medios personales o impersonales con el fin último de estimular la compra de la demanda. En definitiva, la promoción debe atender a tres objetivos básicos: informar (comunicar la existencia del producto, características y ventajas del mismo, así como las necesidades que satisface), persuadir (convencer al cliente potencial de los beneficios que reporta el producto); y recordar (se trata de que los clientes tengan presente que el producto sigue existiendo y que le puede proporcionar nuevas ventajas, evitando de este modo que se adquieran otros productos de la competencia).

La promoción turística de destinos y empresas instaladas en espacios de interior se puede llevar a cabo a través de infinidad de instrumentos que componen lo que viene a denominarse el mix de comunicación: 
- Promoción de ventas: Conjunto de incentivos a corto plazo para estimular e incitar a los consumidores $^{11}$ a visitar un destino turístico y a los intermediarios ${ }^{12}$ a colaborar eficazmente en dicha labor durante un periodo limitado de tiempo.

- Relaciones públicas: Conjunto de programas $^{13}$ para mejorar, mantener o proteger la imagen de una empresa, producto o destino turístico, y crear una conciencia favorable hacia los mismos. Para ello, las relaciones públicas informan constante y regularmente a intermediarios, comunidad local, turistas, prensa, sector privado, entre otros.

- Publicidad: Comunicación no personal y pagada para la presentación y promoción de bienes, servicios o ideas, que lleva a cabo un patrocinador identificado. Este tipo de comunicación se suele hacer a través de medios de masas como la televisión, teletexto, prensa, radio, Internet, pantallas led en destino y centros emisores, cartelería, folletos, etc.

- Buzz marketing (marketing viral): Consiste en transformar a los clientes en prescriptores a través del boca-oreja.

- Marketing de proximidad: Envío de publicidad o información a los teléfonos móviles de los turistas cuando pasan por un determinado lugar (tecnología bluetooth). En la actualidad esta técnica está evolucionando hacia la descarga voluntaria de guías y ofertas de interés para el turista vía mobile a través de Internet o zonas Wi-fi del destino.

- Marketing de guerrilla (marketing radical, extreme marketing, feet-on-the-street): Instrumento a medio camino entre la publicidad (publicidad exterior) y las relaciones públicas (eventos y experiencias). Se trata de generar acontecimientos destinados a sorprender al público en sus actividades cotidianas y/o a despertar rumor.

La elección de un medio u otro de promoción y comunicación dependerá, más aún en turismo rural, de los recursos disponibles, las características del mercado objetivo, el tipo de estrategia de distribución que se utilice y la etapa del ciclo de vida en la que se encuentre el producto turístico.

\footnotetext{
${ }^{11}$ Ofertas y descuentos en el precio, cupón descuento (para un atractivo turístico obtenido en la visita de otro), concursos y loterías (vacaciones gratuitas), regalos por consumo, self liquidating premium (el turista envía pruebas de su estancia y consigue un regalo), free premium (el turista envía pruebas de haber hecho una reserva y consigue un regalo a su llegada), merchandising (comercialización o regalo de material promocional en el destino), etc.

${ }^{12}$ Descuentos al agente de viajes, realización de merchandising por las agencias de viajes, regalos y otros incentivos no monetarios (clientes misteriosos), comisiones, primas, premios, etc.

${ }^{13}$ Los principales programas utilizados son las notas de prensa o publicity (comunicados de prensa que se mandan a los editores de revistas o periódicos para su publicación), ruedas de prensa, dossier, folletos y otras publicaciones, work-shops (encuentros profesionales entre empresarios de un destino y los organizadores de viajes de un mercado emisor), boletines de noticias (publicaciones producidas por las entidades públicas y organismos de gestión de destinos turísticos en las que se proporcionan noticias relacionadas con la actividad turística), fam trips (viajes de familiarización, prospección o formación de un grupo de profesionales del sector turístico emisor al destino que se promociona para conocer directamente su oferta), mecenazgo y patrocinio (inversiones económicas en actividades o eventos que al realizarse generan una transmisión de la imagen y la marca del destino turístico. El mecenazgo transmite una imagen social a largo plazo para un público objetivo restringido, mientras que el patrocinio transmite una imagen comercial a corto plazo para un público amplio), ferias, exposiciones turísticas, congresos, etc.
} 


\subsubsection{Distribución}

La distribución es el instrumento de marketing que pone en relación la producción y el consumo (pone el producto a disposición del consumidor final en el momento y el lugar necesario para su adquisición). Dentro del marketing turístico, los canales o redes de distribución son la estructura que se forma en un mercado turístico por el conjunto de organizaciones para facilitar y poner a disposición de los posibles compradores los productos turísticos (concreción de la venta, confirmación y cobro).

Existen dos estrategias de distribución fundamentales de uso alternativo o combinado: la estrategia de empuje (push) al canal de ventas donde el productor planifica la utilización del canal como instrumento para promover el producto y la estrategia de atracción (pull) del potencial turista donde el productor dirige la promoción del producto directamente al consumidor final, encargándose plenamente de todas las actividades necesarias para estimular la adquisición directa del producto o la atracción del consumidor hacia el canal de distribución.

Si la distribución física de productos consiste en aproximar el producto al cliente, en materia turística la distribución hará referencia al acercamiento y entrega de documentaciones (bonos, billetes, etc.), que justifiquen la adquisición del producto turístico. Sin embargo, para algunas empresas turísticas (restaurantes, agencias de viajes, etc.) la distribución queda en un segundo plano, ganando protagonismo la localización o punto de venta. En cambio, para otros negocios la mera localización no es suficiente y es necesario tener una red de ventas que actúe lejos del lugar de producción (distancia entre consumidor y prestatario, intención de captar nuevos clientes, necesidad de conseguir reservas anticipadas, etc.).

Uno de los mayores fallos que presenta en la actualidad el turismo rural y que incide directamente sobre la ocupación media de los alojamientos es la desorganizada distribución de los productos turísticos. Tradicionalmente, la dispersión y heterogeneidad de las microempresas turísticas rurales ha obligado a comercializar sus productos de forma individual, sobre todo gracias a Internet. Sin embargo, la aparición constante de nuevas ofertas turísticas en infinidad de espacios rurales y naturales, dibuja un escenario excesivamente competitivo para las microempresas rurales y demasiado complejo para el consumidor final, sobre todo si la demanda es de tipo internacional. Por todo ello, en la planificación de espacios turísticos interiores se tiene que apostar decididamente por el desarrollo de actuaciones encaminadas hacia la comercialización conjunta de productos a través de canales de distribución específicos o centrales de reservas propias.

\subsubsection{Precio}

El precio es el monto monetario de intercambio asociado a la transacción que incluye forma de pago (efectivo, cheque, tarjeta, etc.), crédito (directo, con documento, plazo, etc.), descuentos pronto pago, volumen, temporada, recargos, etc. Entre las características básicas del precio destacan las siguientes: permite actuar con rapidez y flexibilidad (instrumento de corto plazo); es el único elemento del marketing mix que procura ingresos, 
el resto provocan gastos; genera importantes repercusiones psicológicas sobre el consumidor o usuario (sensación de calidad y exclusividad del producto); es un poderoso instrumento competitivo en el mercado; y en muchas ocasiones es la única información disponible en las decisiones de compra.

La oferta turística rural está todavía muy lejos del resto de ofertas turísticas con mayor experiencia acumulada a la hora de diseñar estrategias de precio. Este hecho incide directamente sobre la ocupación media de los establecimientos rurales que no son capaces de generar más pernoctaciones, ampliar la estancia media y reducir la estacionalidad. Por todo ello, resulta fundamental el establecimiento de políticas creativas y originales sobre ofertas, descuentos y paquetes fuera de temporada.

\section{CONCLUSIONES}

El diseño de herramientas metodológicas orientadas a la planificación de espacios turísticos de interior resulta necesario desde la dimensión del análisis de los destinos turísticos, a la vez que útil desde el punto de vista empírico y factible como planteamiento de trabajo científico-técnico.

La necesidad de este tipo de metodologías deriva del hecho de que los espacios turísticos de interior deben hacer frente a importantes retos, e incluso amenazas, como son la transposición de modelos de implantación turístico-residenciales propios del litoral, la alienación sociocultural de la población local, la generación de impactos medioambientales y paisajísticos, la pérdida de calidad de vida, el endeudamiento de los entes locales, el abandono de los modos de vida tradicionales, la excesiva dependencia del monocultivo turístico, el sobredimensionamiento de la oferta de alojamiento, la falta de competitividad de las empresas y su insuficiente rentabilidad.

La planificación estratégica resulta de gran utilidad como herramienta basada en una visión a medio y largo plazo que permite adelantarse a los problemas, proponiendo actuaciones concretas que sirvan de base para la correcta gestión de los espacios turísticos de interior.

Asimismo, el desarrollo de metodologías específicas para espacios de interior resulta totalmente factible, a la hora de su desarrollo e implantación, ya que es posible adaptar metodologías en materia de planificación turística a las particularidades intrínsecas de los espacios interiores.

Prueba de todo lo anterior es la propuesta metodológica presentada en este artículo. Una propuesta transversal que apuesta por la integración de los objetivos de desarrollo local, competitividad turística y sostenibilidad territorial, que se afronta en su extenso y amplio desarrollo a través de un enfoque multidisciplinar desde la perspectiva geográfica, económica, empresarial y social y que en suma, contribuye a mejorar los procesos de planificación y gestión de la actividad turística en los espacios de interior. 


\section{REFERENCIAS BIBLIOGRÁFICAS}

ANDREU, N., GALACHO, F. B., GARCÍA, M. y LÓPEZ, D. (2005). "Técnicas e instrumentos para el análisis territorial". En ANTÓN, S. y GONZÁLEZ, F (Coord.): Planificación territorial del turismo. Barcelona: Editorial UOC.

ANTON, S. y GONZÁLEZ, F. (2005). "Fundamentos de planificación territorial”. En ANTÓN y GONZÁLEZ (Coord.): Planificación territorial del turismo. Barcelona: Editorial UOC.

BERNABÉ, A. y VIÑALS, M. J. (1999). "La planificación turística en los espacios naturales y rurales". En VIÑALS y BERNABÉ (Coord.): Turismo en espacios naturales y rurales. Valencia: Ed. Universidad Politécnica de Valencia.

BORDEN, N. H. (1964). "The Concept of the Marketing Mix", Journal of Advertising Research, (4) 2-7.

CÀNOVES, G., HERRERA, L. y VILLARINO, M. (2005). "Turismo rural en España: paisajes y usuario, nuevos usos y nuevas visiones". Cuadernos de Turismo, (15) 63-76.

CONSELLERIA DE TURISME (2007). Plan de Espacios Turísticos de la Comunitat Valenciana. Disponible

en:

http://www.turisme.gva.es/opencms/opencms/turisme/es/contents/planific acion/plan_espacios/plan_espacios.html

GÓMEZ, D. (1994). Ordenación del territorio. Una aproximación desde el medio Físico.

Madrid: Instituto Tecnológico Geominero de España. Editorial Agrícola Española.

INSKEEP, E. (1991). Planificación turística nacional y regional. Madrid: OMT.

IVARS, J. A. (2001). La planificación turística en los espacios regionales en España. Tesis Doctoral. Alicante: Instituto Universitario de Geografía de la Universidad de Alicante.

MCCARTHY, E. J. (1960). Basic Marketing: A Managerial Approach. Homewood, IL: Richard D. Irwin, Inc.

MORALES, J. (1998). Guía práctica para la interpretación del patrimonio. Sevilla: Junta de Andalucía.

ORDUNA, F. J. (2002). "Turismo, patrimonio natural y medio ambiente". Revista de Desarrollo Rural y Cooperativismo Agrario, (4), 95-130.

PARDELLAS, X. (2008). "La gestión de los destinos turísticos rurales en un entorno de competitividad". En PULIDO, J. I.(Coord.): El turismo rural: Estructura económica y configuración territorial en España, Madrid: Editorial Síntesis.

PULIDO, J. I. (2005). "Los retos del turismo rural en España. Orientaciones para la formulación de una política turística rural". En LÓPEZ, T. y LARA, F. (Coord.): Turismo sostenible. Un enfoque multidisciplinar e internacional. Córdoba: Servicio de Publicaciones de la Universidad de Córdoba.

RITCHIE, R. J. B. y RITCHIE, J. R. B. (2002). "A framework for an industry supported destination marketing information system". En Tourism Management, (16) 439-454.

SOLSONA, F. J. (2009). "La planificación turística en espacios rurales". En CROSBY, A. (Coord): Re-inventando el turismo rural. Gestión y desarrollo. Barcelona: Editorial Alertes.

VERA, J. F., LÓPEZ, F., MARCHENA, M. y ANTON, S. (1997): Análisis territorial del turismo. Barcelona: Ed. Ariel. 